\title{
Correction to: Eosinophilic myenteric ganglionitis as a cause of chronic intestinal pseudo-obstruction
}

\author{
Ariadne H. A. G. Ooms ${ }^{1} \cdot J^{\prime}$ Janne Verheij ${ }^{2} \cdot$ Jessie M. Hulst ${ }^{3} \cdot$ John Vlot $^{4} \cdot$ Cynthia van der Starre $^{5} \cdot$ Lissy de Ridder $^{3}$. \\ Ronald R. de Krijger ${ }^{1}$
}

Published online: 17 August 2019

(C) Springer-Verlag GmbH Germany, part of Springer Nature 2019

\section{Correction to: Virchows Arch (2012) 460: 123-127 https://doi.org/10.1007/s00428-011-1183-x}

It has been identified that one of the dosages listed within the above article was incorrectly abbreviated during the production process.

In section 'Clinical history' on Page 124, the article reads: "Major improvement of the infant's condition only occurred after starting anti-inflammatory treatment, using intravenous prednisone and subsequently oral beclomethasone $\mathbf{2 0 0}$ mg three times daily."
This should instead read $\mathbf{2 0 0}$ micrograms, as stated by the authors in the accepted manuscript. Thus the sentence should read:

"Major improvement of the infant's condition only occurred after starting anti-inflammatory treatment, using intravenous prednisone and subsequently oral beclomethasone $\mathbf{2 0 0}$ mcg three times daily."

No further corrections have been made.

Publisher's note Springer Nature remains neutral with regard to jurisdictional claims in published maps and institutional affiliations.

The online version of the original article can be found at https://doi.org/ 10.1007/s00428-011-1183-x

Ariadne H. A. G. Ooms

a.ooms@erasmusmc.nl; A.Ooms@pathan.nl

1 Department of Pathology, Josephine Nefkens Institute, Erasmus MC-University Medical Centre, P.O. 2040, 3000 CA, Rotterdam, The Netherlands

2 Department of Pathology, AMC, Amsterdam, The Netherlands

3 Department of Pediatric Gastroenterology, Erasmus MC - Sophia, Rotterdam, The Netherlands

4 Department of Pediatric Surgery, Erasmus MC - Sophia, Rotterdam, The Netherlands

5 Neonatal and Pediatric ICU, Erasmus MC-Sophia, Rotterdam, The Netherlands 